\title{
Lipoma in the Sigmoid: A Rare Case of Intestinal Obstruction
}

\author{
Moumita Acharya ${ }^{1 *}$, Sibnath Mandal ${ }^{2}$
}

${ }^{1}$ Senior resident, Calcutta national medical college, Kolkata, West Bengal, India

${ }^{2}$ Consultant, peerless Hospital, Kolkata, West Bengal, India

DOI: $10.36347 /$ sasjs.2020.v06i10.002

| Received: 29.09.2020 | Accepted: 12.10.2020 | Published: 17.10.2020

*Corresponding author: Dr. Moumita Acharya

\section{Abstract}

Lipomas of the colon are relatively rare $(0.2 \%$ to $4.4 \%)$ benign mesenchymal tumours, being $2^{\text {nd }}$ to benign adenomatous polyps. Usually seen in the right colon, lipomas can also be seen arising from the submucosa in the sigmoid colon. Usually asymptomatic but when they become large, can produce symptoms of abdominal pain, intussusception, diarrhoea, bleeding per rectum and even obstruction. Here we present a case of colonic obstruction in 49year old female due to a large growth in the sigmoid colon. Initially presenting with features of obstruction, she was evaluated. Colonoscopy revealed an obstructing growth at the sigmoid. Imaging made the diagnosis of possible lipoma of the colon which was further confirmed intra operatively and later biopsy proven. Colonic growths if small in size can be retrieved by endoscopic procedures. But if they attain huge sizes, needs formal laparotomy with segmental resection (to rule out malignancy).

Keywords: Lipomas, diarrhoea, haematochezia, histopathological examination.

Copyright $\odot 2020$ The Author(s): This is an open-access article distributed under the terms of the Creative Commons Attribution 4.0 International License (CC BY-NC 4.0) which permits unrestricted use, distribution, and reproduction in any medium for non-commercial use provided the original author and source are credited.

\section{INTRODUCTION}

Lipomas are benign tumors of the adipocytes. Lipoma of the colon are relatively rare $(0.2 \%$ to $4.4 \%)$ [1]. $70 \%$ located in the right hemi colon (caecum ascending colon sigmoid colon) [2]. Arise from the submucosa of the colon; can be subserosal / intramucosal. Usually asymptomatic but when they become large $(>4 \mathrm{~cm})$, can produce symptoms of abdominal pain, diarrhoea, haematochezia, intussusception and even colonic obstruction [3, 4].

\section{CASE REPORT}

A 49 years old lady presented with complaints of passage of mucoid stools mixed with fresh blood for 2-3months. Associated with intermittent episodes of vague lower abdominal pain with features suggestive of intermittent intestinal obstruction. She is known hypertensive, hypothyroid with right nephrolithiasis and uterine myoma. On admission, patient was hemodynamically stable, afebrile. Per abdominal findings: Lower abdominal distension with tenderness. DRE: revealed no palpable mass, no blood/ stool on fingertip. She was investigated. Blood reports essentially normal.

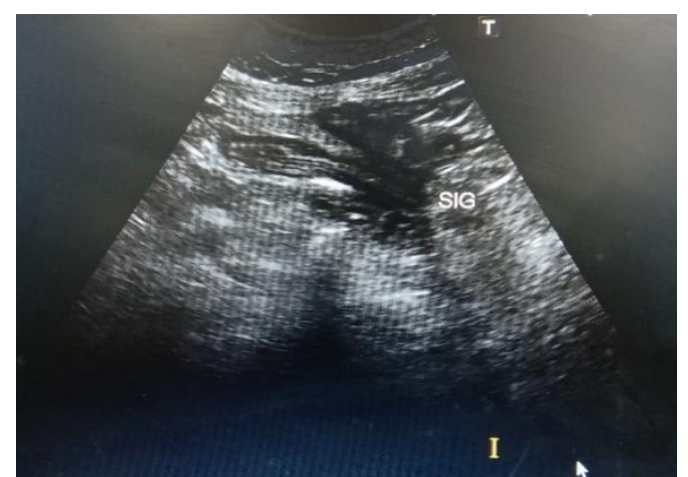

Ultrasonogram abdomen: Hepatomegaly, Focal wall thickening at sigmoid with whirl pattern $\rightarrow$ possible diverticula/ intussusception

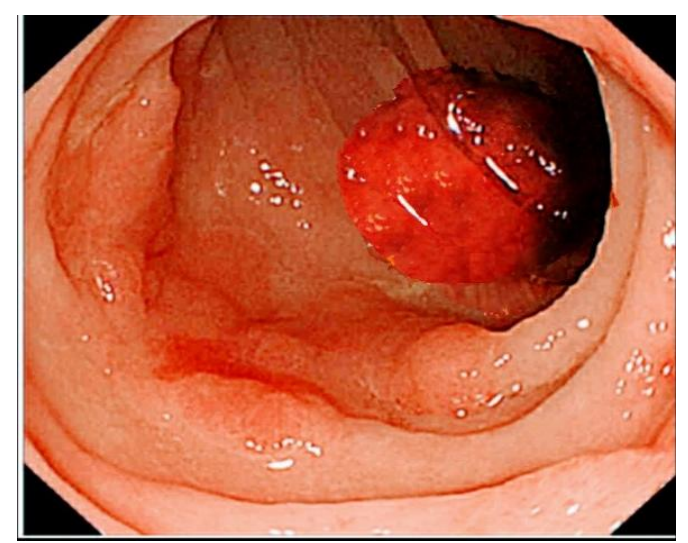

Partial colonoscopy: Large pedunculated polypoidal lesion (?inverted) with stalk $40 \mathrm{~cm}$ above anal verge. Scope could not be passed beyond the lesion 


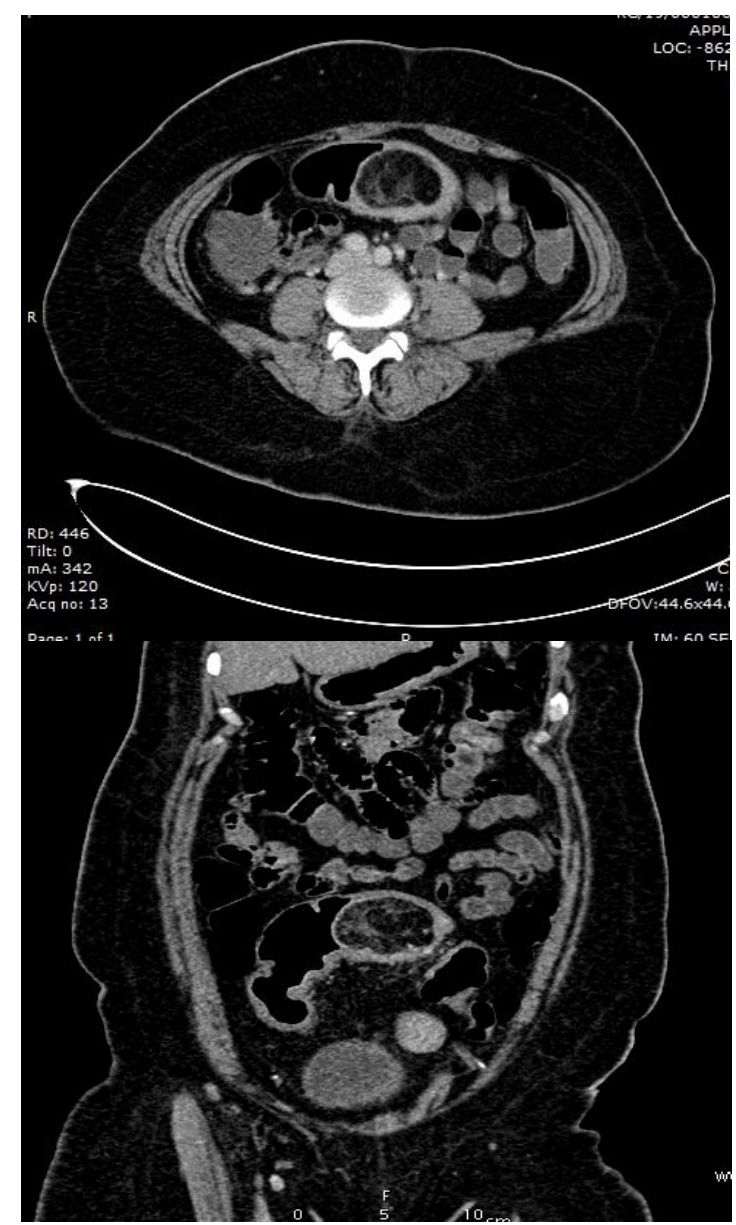

CECT Whole abdomen: Well defined intraluminal relatively fat containing lesion at the descending colon and sigmoid junction having mild amount of heterogenous peripheral fat enhancement $\sim$ possibility of a colonic lipoma Sigmoid colectomy was done as it was an obstructing growth

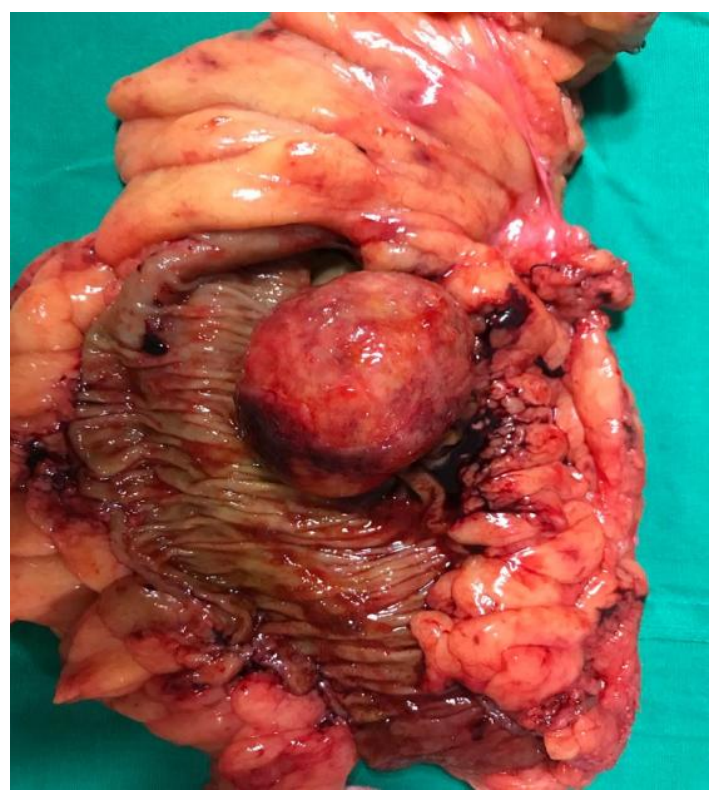

On table specimen showing the polypoidal growth

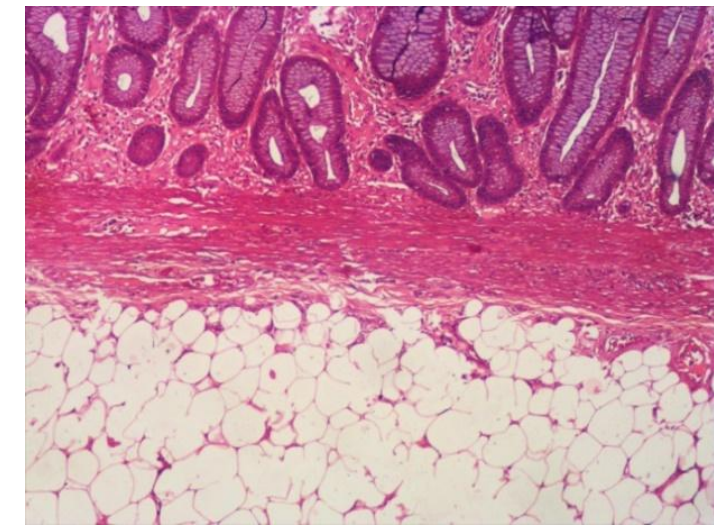

Histopathology: Sections through the polypoidal lesion show collagenised submucosa with a benign submucosal lipoma protruding into the lumen as a polypoidal mass. Overlying muscularis mucosa is thickened. Mucosa is ulcerated with ulcer base granulation tissue

\section{DISCUSSION}

Colonic growths can be retrieved by endoscopic procedures if they are small in size. But if they attain huge sizes $(>4 \mathrm{~cm})$, needs formal laparotomy with segmental resection. Narrow Band Imaging facility was not available in the setup, hence not done. Biopsy not taken as: (i) It was an obstructing growth: would require removal anyway (iii) Chance of bleeding (in case the lesion was a GIST) (iii) Deep biopsies would be required: scope could not be negotiated beyond the tumor (iv) Biopsy may not be conclusive.

\section{CONCLUSION}

This is a case of colonic obstruction in 49year old hypertensive female due to large growth in the sigmoid colon initially presenting with features of obstruction. Colonoscopy revealed an obstructing growth at the sigmoid. CT made the diagnosis of (probable) lipoma of the colon which was further confirmed intra operatively and by histopathological examination.

\section{Declaration of Patient Consent}

The authors certify that they have obtained all appropriate patient consent forms. In the form the patient has given her consent for her images and other clinical information to be reported in the journal. The patient understand that her name and initials will not be published and due efforts will be made to conceal her identity, but anonymity cannot be guaranteed.

Financial support and sponsorship: Nil.

Conflicts of interest: There are no conflicts of interest.

\section{REFERENCE}

1. Vecchio R, Ferrara M, Mosca F, Ignoto A, Latteri F. Lipomas of the large bowel. Eur J Surg. 1996; 162:915919.

2. Nallamouthu G, Adler GD. Large colonic lipoma. Gastroenterol Hepatol. 2011; 7(7):490-492.

3. Castro EB, Stearns MW. Lipoma of the large intestine: a review of 45 cases. Dis colon rectum.1972; 15:441-444.

4. Gordon RT, Beal JM. Lipoma of the colon. Arch surg. 1978; 113:897-899. 